\title{
ODONTOMA COMPLEXO: RELATO DE CASO CLÍNICO E ACOMPANHAMENTO DE SEIS ANOS
}

Kleber Lisboa ARAUJO, Felipe da Silva PERALTA, Jill Guilherme QUADROS, Antônio Eugênio MAGNABOSCO NETO

O Odontoma complexo é um tumor odontogênico benigno, formado por tecidos dentários que se apresenta como uma massa calcificada, de forma arredondada ou irregular, e localizado preferencialmente na região de molares. $\mathrm{O}$ tratamento da lesão consiste na remoção cirúrgica. Este trabalho tem como objetivo relatar um caso clínico de Odontoma complexo, tratado e acompanhado durante seis anos. Paciente do sexo feminino, 19 anos, leucoderma, compareceu ao ambulatório do Serviço de Cirurgia e Traumatologia Bucomaxilofacial do Hospital Municipal São José (HMSJ), relatando aumento de volume em mandíbula e dificuldade de abertura bucal. $\mathrm{Na}$ avaliação clinica e radiográfica, suspeitou-se de um Odontoma, sendo indicada a biopsia da lesão. Durante a enucleação da lesão, ocorreu fratura patológica da mandíbula, sendo realizado bloqueio maxilo-mandibular por 30 dias. A peça cirúrgica foi encaminhada para o serviço de patologia do HMSJ que confirmou a hipótese diagnóstica. Foram realizados acompanhamentos clínico e radiográfico nos períodos de 30, 90, 180 e 360 dias do pós-operatório. Passados seis anos da cirurgia, uma nova avaliação clínica e radiográfica foi realizada para observar a consolidação da fratura e a remodelação óssea no local da lesão. Baseado nesse tempo de acompanhamento pode-se concluir que o tratamento cirúrgico do Odontoma complexo foi eficiente.

Palavras-chave: Odontoma; Anomalias Dentárias; Malformações Dentárias. 